\title{
ICT-based applications to improve social health and social participation in older adults with dementia. A systematic literature review
}

Ángel C. Pinto-Bruno, J. Antonio García-Casal, Emese Csipke, Cristina JenaroRío \& Manuel Franco-Martín

To cite this article: Ángel C. Pinto-Bruno, J. Antonio García-Casal, Emese Csipke, Cristina Jenaro-Río \& Manuel Franco-Martín (2016): ICT-based applications to improve social health and social participation in older adults with dementia. A systematic literature review, Aging \& Mental Health

To link to this article: http://dx.doi.org/10.1080/13607863.2016.1262818

Published online: 12 Dec 2016.

Submit your article to this journal $\pi$

Q View related articles 5

View Crossmark data \lceil 


\title{
ICT-based applications to improve social health and social participation in older adults with dementia. A systematic literature review
}

\author{
Ángel C. Pinto-Bruno ${ }^{\mathrm{a}, \mathrm{b}}$, J. Antonio García-Casal (D) ${ }^{\mathrm{a}, \mathrm{b}}$, Emese Csipke ${ }^{\mathrm{d}}$, Cristina Jenaro-Río ${ }^{\mathrm{a}}$ and \\ Manuel Franco-Martín (iD ${ }^{a, c}$ \\ ${ }^{\mathrm{a}}$ Department of personality, evaluation and psychological treatment, University of Salamanca, Salamanca, Spain; ${ }^{\mathrm{b}}$ Department of Research \& \\ Development, INTRAS Foundation, Zamora, Spain; 'Department of Psychiatry, Zamora Hospital, Zamora, Spain; ' ${ }^{\mathrm{d}}$ Division of Psychiatry, University \\ College London, London, United Kingdom
}

\begin{abstract}
Objectives: Information and communication technologies (ICT) developers, together with dementia experts have created several technological solutions to improve and facilitate social health and social participation and quality of life of older adults living with dementia. However, there is a need to carry out a systematic literature review that focuses on the validity and efficacy of these new technologies assessing their utility to promote 'social health' and 'active ageing' in people with dementia.

Method: Searches in electronic databases identified 3824 articles of which 6 met the inclusion criteria and were coded according to their methodological approach, sample sizes, type of outcomes and results.

Results: Six papers were identified reporting the use of 10 different interventions with people with dementia. Qualitative studies (four) showed a benefit of the use of technologies to foster social participation in people with dementia. At the same time, barriers to a widespread use of these technologies in this population were identified. A quantitative study and a mixed-method study with quantitative outcomes showed that ICT-based interventions promote more social behaviours than non-technology-based interventions.

Conclusions: In the last years, several technological devices for living independently and fostering social health and social participation in people with dementia have been developed. However, specific outcome measures to assess social health and social participation are needed. Even though the analysed studies provided some evidence-base for the use of technology in this field, there is an urge to develop high quality studies and specific outcome measures.
\end{abstract}

\section{ARTICLE HISTORY}

Received 3 June 2016

Accepted 14 November 2016

\section{KEYWORDS}

Dementia; technology; social health; social participation; older adults

\section{Introduction}

According to the World Health Organization (2015) about 47 million people suffer from dementia around the world. The World Alzheimer Report (Alzheimer's Disease International, 2015) estimates that there are about 10.5 million people living with dementia in Europe with an estimated prevalence rate of $5.9 \%$. Every year there are 8 million people newly diagnosed. Mild cognitive impairment $(\mathrm{MCl})$ is described as a series of symptoms that, while not seriously interfering in daily life, increase risk of dementia (Alzheimer's Society, 2015). In a review that was carried out by Roberts and Knopman (2013), prevalence estimates of $\mathrm{MCl}$ ranged from $16 \%$ to $20 \%$ of people over 65 around the world. In addition to this, according to Panza et al. (2010), there is comorbidity between depression and $\mathrm{MCl}$. Women with $\mathrm{MCl}$ are at greater risk of social isolation (Artero et al., 2008). As a matter of fact, several authors have proved that loneliness, social isolation and also the presence of negative social interactions are related to a higher probability of having $\mathrm{MCl}$ (Cacioppo \& Hawkley, 2003; Shankar, Hamer, McMunn, \& Steptoe, 2013; Wilson et al., 2007). Wang, He, and Dong (2015) suggested that more interventions fostering social networks and social participation in older adults are necessary to prevent cognitive decline.

Huber et al. (2011) proposed a definition of health that includes several dimensions of social health such as the people's capacity to fulfil their potential and obligations, the ability to manage their life with some degree of independence despite a medical condition, and the ability to participate in social activities including work. This definition has created the need to widen the scope of psychosocial studies about health, including new types of outcome measures in an area that used to focus on cognitive functions, mood and activities of daily living. Adapting to the environment and participation in social activities are central aspects of an effective management of life that leads to being involved with meaningful activities, and social interaction, social ties and meaningful relationships (Huber et al., 2011). Social participation is regarded as a key determinant of successful and healthy ageing (Levasseur, Richard, Gauvin, \& Raymond, 2010). Even though some authors have been using this term in relation to the concepts of social interaction, social inclusion or social activity, Levasseur et al. (2010) described it as the persons involvement in activities that provide interactions with others in society. This inconsistent use of the term shows that a clear definition of social participation is still needed (Piskur et al., 2014).

In 2015, the global population was ageing at a rate not seen in the past (United Nations, 2015). Europe is the continent where this ageing process is likely to be of major significance in the coming decades (Eurostat, 2015). In the last 
years, 'active ageing' is being promoted by governments and institutions (World Health Organization, 2015). The World Health Organization defines 'active ageing' as the process of optimising opportunities for health, participation and security in order to enhance older adults' quality of life. This definition encompasses a series of related concepts; the word 'active' refers to continuing participation in social, economic and cultural activities, being older adults a contributory element in families, communities and nations. The active ageing process goes further than physical well-being or managing daily life activities, it pursues the inclusion of older adults in society. On the other hand, 'active ageing' seeks to maintain older adults' autonomy and independence through the promotion of integral health (physical, mental and social wellbeing) (World Health Organization, 2015). Another concept highly linked to active ageing is 'ageing in place", which was defined by Davey, de Joux, Nana, \& Arcus $(2004$, p. 20) as the ageing policies of remaining living in the community, with some level of independence, rather than in residential care. These policies have been promoted by the World Health Organization and the Organization for Economic Co-operation and Development due to several studies that have shown that the economic costs of ageing in place are lower than those of ageing in residential care homes (Chappell, Dlitt, Hollander, Miller, \& McWilliam, 2004). Furthermore, 'ageing in place' enables the maintenance of social connections to family and friends improving the quality of life of older adults (Wiles, Leibing, Guberman, Reeve, \& Allen, 2011).

In the last decade, information and communication technologies (ICT) developers have been working for the implementation of interventions creating several technological solutions to improve and facilitate ageing in place, social participation, personal autonomy, independence and quality of life of older adults (Padilla y Sánchez-López, 2007). García-Lizana (2013) holds that a new integrated model of health and social services focusing on citizen-patient is necessary to the future of our health systems and the only way to make them efficient and dynamic is using new technologies. According to Doherty and Mendenhall (2006), citizen-patient health care model is defined as a way to engage patients, families and communities as coproducers of health and health care. It goes beyond the activated patient to the activated community, with professionals acquiring community organizing skills for working with individuals and families who see themselves as citizens and health care builders of health in the clinic and community rather than merely as consumers of medical services.

Several ICT-based approaches and innovations have been developed in the field of older adults' care (Padilla, 2008). These, can be grouped as technological aids and ambient assisted-living systems (technological gadgets that help older adults with certain daily life activities in order to improve their quality of life); cognitive assessment or cognitive interventions based on ICT (adapting pencil and paper batteries to technological environments, or creating new ICT-based interventions) to provide cognitive and emotional support for older adults and their carers (Boots, de Vugt, van Knippenberg, Kempen, \& Verhey, 2014; Franco-Martín et al., 2011; García-Casal et al., 2016; Oriani et al., 2003); and technologies and interventions to foster older peoplés social participation and the creation and maintenance of social relationships through technology (Padilla, 2008) (Appendix 1). However, some factors may affect the implementation of these systems like their design (Marcos, 2002), acceptability (Placencia,
2001), accessibility (Jiménez-Lara, 2000) and lack of usability studies.

Due to the diversity of technological solutions developed to foster social participation, this systematic literature review aims to assess the effects of ICT-based interventions evaluating their utility to promote 'active ageing' and 'social health' in people with dementia.

\section{Method}

A systematic literature search of four scientific databases was performed, covering literature published up to May 2016.

\section{Types of interventions and participants}

This article focuses in the social aspect of existing ICT interventions whose aim is to maintain, facilitate and improve social participation, inclusion and networks of people living with dementia. This included different technology hardware such as computers, laptops, mobile phones, monitoring devices and tablets. The aim of these technologies is to avoid the social isolation of people living with dementia encouraging their social participation and social contacts in the community through leisure and cognitive activities.

\section{Search engines}

Searches in electronic databases for this systematic review were conducted in May 2016 using Psyclnfo, PubMed, CINAHL with full text and Scielo.

\section{Search terms}

A unified search term using Boolean operators was applied for three out of four databases (Psyclnfo, PubMed and CINAHL with full text): (aged or dementia or $\mathrm{MCl}$ or Mild Cognitive Impairment or elderly or old or older adults) and (active aging or active aging or cognitive stimulation or psychosocial or social or aging in place) and (computer or computing or ICT or technology). As Scielo database does not allow a unified search using Booleans, a combination cascade of terms was used (Table 1).

\section{Inclusion criteria}

(1) Qualitative and quantitative research which analyses the effect of ICT-based interventions to facilitate social participation and social health among people living with Dementia.

(2) Studies whose participants are aged 55 years old or older with a diagnosis of dementia (both, living in the community or in residential care facilities).

(3) Publications written in English.

Table 1. Keywords for search in Scielo.

\begin{tabular}{lll}
\hline Sample & Type of intervention & Technologies \\
\hline Aged & Active aging & Computer \\
Dementia & Active aging & Computing \\
Elderly & Ageing in place & ICT \\
$\mathrm{MCl}$ & Cognitive stimulation & Technolog* \\
$\mathrm{MCl}$ & Psychosocial & \\
Old & Social & \\
Older adults & & \\
\hline
\end{tabular}

Note: ${ }^{*}$ is a Boolean operator used to search for terms with different endings. 




Figure 1. Flowchart of the search strategy.

\section{Exclusion criteria}

(1) Results coming from mixed interventions (both, technology-based and non-technology-based interventions) that did not specify the effect of ICT-based interventions on social outcomes.

(2) Studies that do not report data about social outcomes.
(3) Articles whose population differ from our target population (older adults in general, Parkinson disease, schizophrenia, Huntington, HIV, smokers, ...).

\section{Selected studies}

The search yielded 3824 papers, of which 468 duplicates were automatically removed; other duplicates were removed in the following steps (321). The first author checked the remaining 3035 titles and abstracts to determinate their relevance. Other three authors also checked one third of the titles and abstracts each. The final inclusion of papers was discussed in a consensus meeting, in case of discrepancies the articles were considered again until consensus was reached. This first screening resulted in a total of 68 relevant papers; those articles were then assessed by two authors on the basis of abstracts and full copies of the article when needed. Finally, after careful reading, researchers agreed that six articles met the inclusion criteria (see Figure 1).

\section{Data analysis and synthesis}

Data on types of ICT applications, sample size and characteristics, dropouts and measures were extracted from the selected studies and classified in an ad-hoc table (see Table 2). Data coding was conducted by the first author with the second author supervision, when these authors could not reach an agreement about the inclusion of papers a third author with expertise in the field was included in a consensus meeting.

Due to the heterogeneous characteristics of the included studies, a narrative synthesis of the qualitative studies was performed according to Lipsey and Wilson's (2001) recommendations, and the quantitative studies' findings were described in the results section.

\section{Quality appraisal}

To assess the quality of the qualitative selected studies we used the Critical Appraisal Skills Programme (CASP) guidance in order to distinguish the studies in terms of overall methodological quality (Spittlehouse, 2000). The criteria of CASP Qualitative Checklist enable to assess the trustworthiness, relevance and results of published qualitative papers (CASP, 2015). This checklist consists of 10 questions designed to help researches think about rigour and relevance of qualitative research; this appraisal included questions such as are the aims described?, is there a statement of the findings? and is there description of the sample? Every question has to be answered with 'yes', 'no' and 'can't tell'. Afterwards, a total score from 0 to 10 was calculated for every study included in

Table 2. CASP Qualitative Checklist.



Notes: $1=$ yes; $0=$ no; n.a. $=$ not applicable. 
the review, allowing the authors to compare the quality of the studies.

\section{Results}

\section{Characteristics of examined studies}

All studies selected were published between 2006 and 2013. They were conducted in four European countries (United Kingdom, the Netherlands, Sweden and Finland). Four of the studies approaches were qualitative while one was a mixedmethod study and the last one a quantitative study (see Table 3).

Different instruments and outcome measures were used to assess the outcomes. Four of them used interviews, two used focus groups or workshops, two used different types of behavioural observations and two used quantitative data in order to categorise their participants and outcomes. Turning to the technologies used in the interventions, most of the studies included several devices in each intervention. One of them used four different devices for the two areas of intervention included in the studio: improvement of quality of life and experienced autonomy of the persons with dementia (sensors, web interface, a hub and a cognitive assistant) (Meiland et al., 2007). Two other studies described the use of a touch screen computer (Astell et al., 2010; Nijhof, van Hoof, van Rijn, \& van Gemert-Pijnen, 2013). One paper assessed the use of 29 different technological devices (Riikonen, Paavilainen, \& Salo, 2013). Finally, a study assessed the use of television, radio and telephone in a technology-based leisure activity for people living with dementia (Nijhof et al., 2013).

The ICT intervention was implemented in the regular living environments in three out of six of the studies, while one took place in a nursing home and two were implemented both in the regular living environment and in public spaces.

\section{Characteristics of participants}

The studies comprised a total sample of 79 people living with dementia. Sample sizes varied from 18 to 34 . Most of the studies utilised convenience sampling, and most of the participants were women. Four of the studies included the perceptions of carers.

\section{Dependent variables and outcomes measures}

Due to the lack of a clear definition of social participation, the operationalization of the concept in the selected studies was heterogeneous. None of the articles selected used a quantitative outcome measure to assess all of the levels included in the social participation concept (social interaction, social inclusion, etc.).

In the qualitative method papers, the effects of ICT use on social variables were examined through interviews exploring the effects of technologies in people with dementia and their social networks. Meiland et al. (2007) focused on the needs from technology support for social contacts. Riikonen et al. (2013) analysed the importance of the social network for the use of technology, and the effect of the technology in the attitude and personality of people with dementia. The study carried out by Brittain, Corner, Robinson, and Bond (2010) analysed how technology non-specifically designed for people with dementia could encourage them to participate in the society.

Turning to the mixed-method study and the quantitative study, the outcome measures used to assess social health and social participation were limited to some aspects of the whole concepts. Nijhof et al. (2013) used the Oshkosh Social Behaviour Coding (OSBC) scale, in order to answer the research questions related to the occurrence of social behaviour during the intervention. This scale includes both verbal and nonverbal, social and non-social behaviour, which are in 21 items (Lunsman, McFadden, \& Andel, 2007). By contrast, in Astell et al. (2010), a coding or verbal and nonverbal behaviour were measured through online observations from videotapes by two blinded researchers. Verbal behaviour was categorized in two groups: choosing with prompt (amount of times the person with dementia chose what they wanted to talk) and initiation (when the person with dementia made the first comment on viewing/listening to new stimulus). Nonverbal behaviour was categorized in four groups: singing, moving to music, pointing to draw attention and laughter. Afterwards, using a behavioural software package, the data were quantitatively analysed.

\section{Study quality}

The methodical quality of the studies was poor. The total score for all studies on each question of the CASP checklist ranged from $0 / 6$ (relationship between researcher and participants) to $6 / 6$. The average score was 7 , equivalent to a $70 \%$ of the possible marks (Table 2).

\section{Quantitative findings}

The results provided by Astell et al. (2010) regarding the utility of an ICT-based reminiscence intervention (CIRCA) compared with a non-ICT based reminiscence intervention (TRAD) showed that people with dementia using CIRCA made more choices $(t(10)=3.6717, p<.005)$. The people with dementia who used the non-technological reminiscence programme spent more time asking direct questions $(t(10)=3.13, p<$ $.01)$ and showed lower levels of initiation of conversation $(z=$ 2.03, $p<.05)$. Turning to the nonverbal measures, people with dementia sang more with CIRCA than with $\operatorname{TRAD}(t(10)=$ $2.191, p<.05)$.

Nijhof et al. (2013) compared two leisure activities, a technology-supported one (The Chitchatters, CC) and a non-technology supported one (The Question Game, QG). The results reported than the mean of social behaviours were lower using the CC than the QG; however, the difference was not statistically significant (CC Mean $=5.09, \mathrm{SD}=3.31$; $\mathrm{QG}$ Mean $=7.41$, $\mathrm{SD}=4.03 ; p<.15)$.

\section{Discussion}

This systematic review is, to our knowledge, the first to assess the effects of ICT solutions on the social health of people living with dementia encouraging their participation in social activities. It is necessary to develop, operationalise and describe the areas that social health as a concept should include; the lack of a strong conceptualisation and operationalisation of the Huber et al. (2011) dimensions of social health makes it difficult to hold a reliable approach to this field. We have defined social health as the capacity of people living 


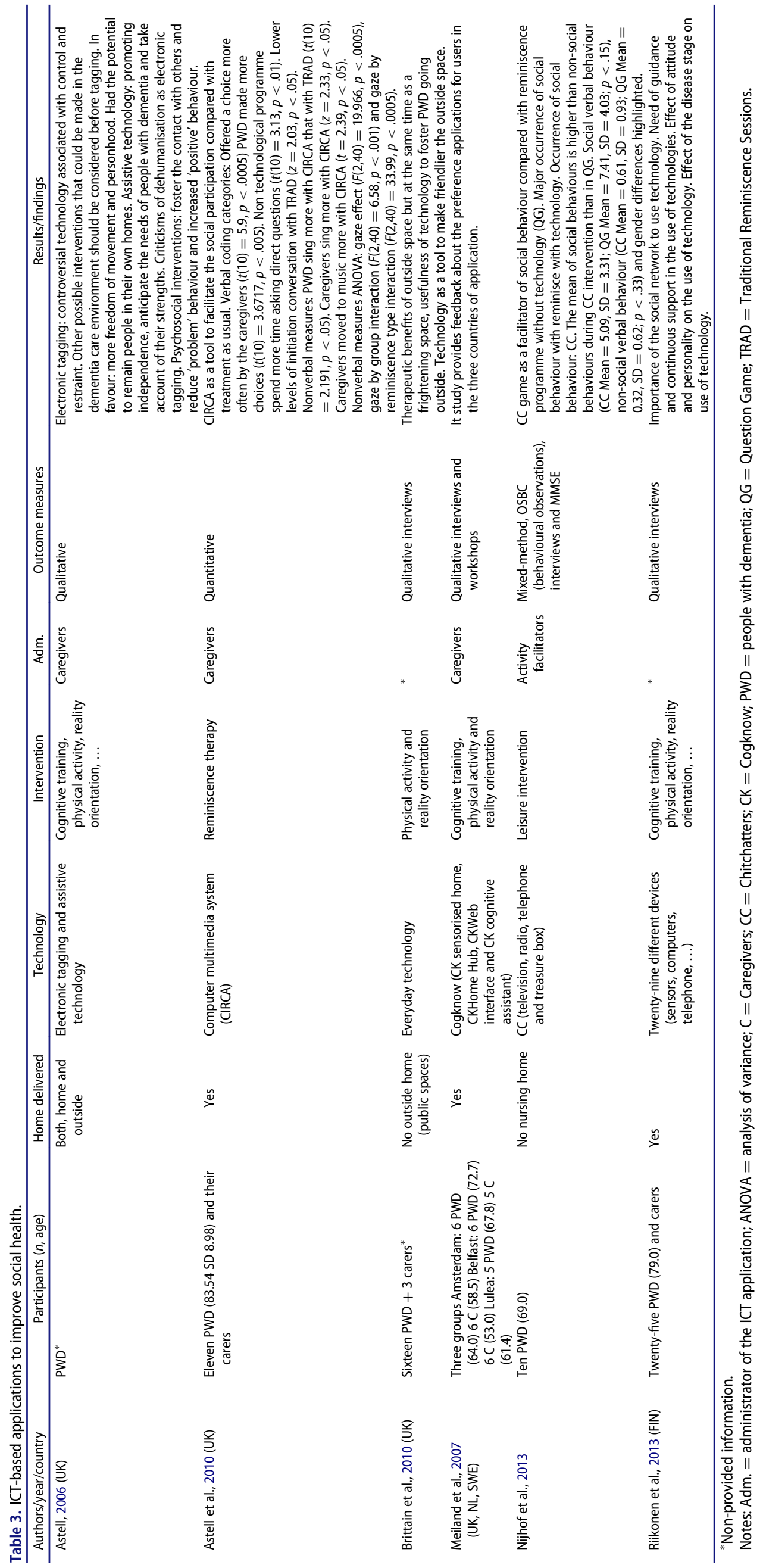


with dementia to actively participate in social networks within their communities.

Some reviews have been carried out by different authors in the last years (Chen \& Schulz, 2016; Dickens, Richards, Greaves, \& Campbell, 2011), which provide emerging evidence to support the use of ICT to foster social participation in older adults with dementia and cognitive impairment (Chen \& Schulz, 2016). However, as this review shows, that evidence has not been tested in methodologically robust clinical trials.

The potential for developing technological solutions to meet the needs of an ageing population is increasingly being recognised (Astell et al., 2010). On the other hand, the great variability in ICT's themselves (where systems using several technological devices as computers, mobiles phones, alarm gadgets, etc. are treated as equals) makes it difficult to classify the interventions into homogeneous groups to compare them.

In the articles analysed in this review, the technologies used for the alleviation of social isolation include among other electronic tagging (Astell, 2006), sensorised homes (Meiland et al., 2007) and the alternative use of regular computers, adapting their components to the needs of people with dementia (Astell et al., 2010; Riikonen et al., 2013). This variability, again, may magnify the challenges to use technologies by people with dementia and those who care for them (Astell et al., 2010) taking into account that most of the people living with dementia and their carers have no extensive experience using technology and that they have to learn how to manage most of the technological gadgets used in these interventions (Placencia, 2001).

According to this systematic search, there is a wide range of interventions for people with dementia using technologies. While Nijhof et al. (2013) explored the use of technologybased leisure activities developed for people with dementia including four interactive objects in order to stimulate social behaviour in groups, Astell et al. (2010) used technology in a reminiscence program (CIRCA) and in a dyad (people with dementia and their carer). On the other hand, Brittain et al. (2010) were interested in how technologies of place mediate between people with dementia and their physical and social environment, defined as 'universal' technologies that are intended for general use, and not only for specific groups (Hansson, 2007).

These interventions show how different approaches and technologies can contribute positively to tackling the problems faced by people with dementia and could improve their social wellbeing (Astell, 2006).

The limited examination of the general concept of social health and social participation as constructs are a barrier to develop appropriate outcome measures. Sansoni, Marosszeky, Sansoni, and Fleming (2010) in their 'Final report for an effective assessment of social isolation' recommended the use of the Lubben Social Network Scale, the Jong-Gierveld Loneliness Scale, the Medical Outcomes Study Social Support Survey and the Multidimensional Scale of perceived Social Support none of which are specific for social health or social participation. However, none of these scales were used in the selected studies which tried to overcome the absence of specific outcome measures developing tailored qualitative outcomes to assess the views of people with dementia (Brittain et al., 2010).

The findings of this review suggest that people with dementia can benefit from ICT interventions and there are different technologies and interventions that could help them to maintain, facilitate and create social networks. However, further research on this topic is urgently needed in order to provide insights into which approaches are the most useful for people with dementia to increase their social participation.

\section{Limitations}

The conclusions drawn from this review must be considered in the context of some limitations. This review focused in the social health aspects of psychosocial interventions with ICT for people living with dementia. While there is evidence that this type of treatments could be beneficial for older adults (Chen \& Schulz, 2016), there is a lack of high quality studies specific for people with dementia; thus, the conclusions of this systematic literature review are based on limited evidence. Even though some interventions have been developed for this specific target population, this lack of high quality experimental studies makes it impossible to currently assess the conveniences or inconveniences of using technologies to foster social health. In addition, as the studies were heterogeneous in terms of design, sample sizes, methods and interventions, it was impossible to statistically pool the data to perform a quantitative meta-analysis to explore the evidence of the effectiveness of the treatments for social health of people living with dementia.

\section{Conclusions}

Even though the concept of social health is relatively new in the dementia area, it is surprising the lack of papers assessing this fundamental aspect of psychosocial interventions. The scarce evidence gathered in this review shows promising results based in mostly qualitative studies. The two studies that provided quantitative results show that ICT-based interventions promote more social behaviours than the non-ICT-based interventions used in the control group traditional ones.

Although technology has been included in several psychosocial interventions during the last decades, most of the ICTbased interventions focused in cognitive decline (ICT-based cognitive interventions) and daily life activities (assistive technologies).

There is a need to develop specific outcome measures to assess all the aspects related to social health as a whole in psychosocial interventions with people with dementia. Further research is also needed in this area and there is also a need for medium- and long-term follow-ups to examine longer term intervention effects. Most importantly what we need are high quality randomised controlled trials.

\section{Acknowledgments}

Ángel Custodio Pinto-Bruno, the corresponding author, had full access to all the data in the study and has final responsibility in the decision to submit it for publication.

\section{Disclosure statement}

Ángel Custodio Pinto-Bruno and Manuel Franco-Martín developed the original idea. Ángel Custodio Pinto-Bruno, Jesús Antonio García-Casal and Manuel Franco-Martín performed the search strategy, extracted data, and wrote the manuscript. Cristina Jenaro-Rio and Emese Csipke contributed to the drafts of the paper and provided valuable comments during the process of writing this manuscript. The authors have no competing interests. 


\section{Funding}

This review is part of PRIDE (Promoting independence in Dementia) a programme funded by the Economic and Social Research Council to research dementia care in the UK and EhcoBUTLER, a project funded by the European Commission H2020 [grant number 643566].

\section{ORCID}

J. Antonio García-Casal iD http://orcid.org/0000-0003-0533-4918 Manuel Franco-Martín (iD http://orcid.org/0000-0002-3639-2523

\section{References}

Alzheimer's Society (2015). Dementia UK 2015. London: Alzheimer's Society. Retrieved from https://www.alzheimers.org.uk/site/scripts/down load_info.php?filelD $=2$

Alzheimer's Disease International (2015). World Alzheimer Report 2015. London: Alzheimer's Disease International. Retrieved from https:// www.alz.co.uk/research/world-report-2015

Artero, S., Ancelin, M.L., Portet, F., Dupuy, A., Berr, C., Dartigues, J.F., ... Ritchie, K. (2008). Risk profiles for mild cognitive impairment and progression to dementia are gender specific. Journal of Neurology Neurosurgery \& Psychiatry, 79(9), 979-984. doi:10.1136/jnnp.2007.136903

Astell, A.J. (2006). Technology and personhood in dementia care. Quality in Ageing, 7(1), 15-25. Retrieved from http://dx.doi.org/10.1108/ 14717794200600004

Astell, A.J., Ellis, M.P., Bernardi, L., Alm, N., Dye, R., Gowans, G., \& Campbell, J. (2010). Using a touch screen computer to support relationships between people with dementia and caregivers. Interacting with Computers, 22(4), 267-275. doi:10.1016/j.intcom.2010.03.003

Boots, L.M., de Vugt, M.E., van Knippenberg, R.J., Kempen, G.I., \& Verhey, F. R. (2014). A systematic review of Internet-based supportive interventions for caregivers of patients with dementia. International Journal of Geriatric Psychiatry, 29(4), 331-344. doi:10.1002/gps.4016

Brittain, K., Corner, L., Robinson, L., \& Bond, J. (2010). Ageing in place and technologies of place: The lived experience of people with dementia in changing social, physical and technological environments. Sociology of Health \& Illness, 32(2), 272-287. doi:10.1111/j.14679566.2009.01203.x

Cacioppo, J.T., \& Hawkley, L.C. (2003). Social isolation and health, with an emphasis on underlying mechanisms. Perspectives in Biology and Medicine, 46(Suppl 3), S39-52. doi:10.1353/pbm.2003.0063

Chappell, N.L., Dlitt, B.H., Hollander, M.J., Miller, J.A., \& McWilliam, C. (2004). Comparative costs of home care and residential care. The Gerontologist, 44(3), 389-400. doi:10.1093/geront/44.3.389

Chen, Y.-R.R., \& Schulz, P.J. (2016). The effect of information communication technology interventions on reducing social isolation in the elderly: A systematic review. Journal of Medical Internet Research, 18 (1), e18. doi:10.2196/jmir.4596

Critical Appraisal Skills Programme-CASP. (2015). Qualitative checklists. Oxford. Retrieved from http://www.casp-uk.net/\#!checklists/cb36)

Davey, J.A., de Joux, V., Nana, G., \& Arcus, M. (2004). Accommodation options for older people in Aotearoa/New Zealand: Centre for housing research christchurch. Retrieved from https://www.beehive.govt.nz/ sites/all/files/Accomodation\%200ptions\%20for\%200lder\%20People. pdf

Dickens, A.P., Richards, S.H., Greaves, C.J., \& Campbell, J.L. (2011). Interventions targeting social isolation in older people: A systematic review. BMC Public Health, 11, 647-647. doi:10.1186/1471-2458-11-647

Doherty, W.J., \& Mendenhall, T.J. (2006). Citizen health care: A model for engaging patients, families, and communities as coproducers of health. Families, Systems, \& Health, 24(3), 251-263. doi:10.1037/10917527.24.3.251

Eurostat (2015). Statistics explained. Retrieved from http://ec.europa.eu/ eurostat/statistics-explained/index.php/ Population_structure_and_ageing

Franco-Martín, M., González Palau, F., Ruiz, Y., Vargas, E., Solis, A., Mellado, J.G., ... Bartolomé, L. (2011). Usability of a cognitive (Gradior) and physical training program based in new software technologies in patients with mild dementia, mild cognitive impairment and healthy elderly people: Long Lasting Memories preliminary findings. Neuroscience Letters, 500, e6. ISSN 0304-3940. doi:10.1016/j.neulet.2011.05.079
García-Casal, J.A., Loizeau, A., Csipke, E., Franco-Martín, M., PereaBartolomé, M.V., \& Orrell, M. (2016). Computer-based cognitive interventions for people living with dementia: A systematic literature review and meta-analysis. Aging \& Mental Health, 1-14. doi:10.1080/ 13607863.2015.1132677

García-Lizana, F. (2013). Cooperación para la innovación europea en el envejecimiento activo y saludable: De la política a la acción [European innovation partnership on active and healthy aging: moving from policy to action]. Gaceta Sanitaria, 27, 459-462. Retrieved from http://dx. doi.org/10.1016/j.gaceta.2012.09.005

Hansson, S.O. (2007). The ethics of enabling technology. Cambridge Quarterly of Healthcare Ethics, 16(03), 257-267. Retrieved from http://dx.doi. org/10.1017/S0963180107070296

Huber, M., Knottnerus, J.A., Green, L., Horst, H.v.d., Jadad, A.R., Kromhout, D.,... Smid, H. (2011). How should we define health? BMJ, 343, d4163. doi:10.1136/bmj.d4163

Jiménez-Lara, M. (2000). Accesibilidad a la red [The Web accesibility]. Boletín del Real Patronato sobre Discapacidad. 40, 16-26.

Levasseur, M., Richard, L., Gauvin, L., \& Raymond, É (2010). Inventory and Analysis of Definitions of Social Participation Found in the Aging Literature: Proposed Taxonomy of Social Activities. Social Science \& Medicine, 71(12), 2141-2149. Retrieved from http://doi.org/10.1016/j. socscimed.2010.09.041

Lipsey, M.W., \& Wilson, D.B. (2001). Practical meta-analysis. Thousand Oaks, CA: Sage Publications. ISBN-13: 978-0761921684.

Lunsman, M., McFadden, S.H., \& Andel, R. (2007, November). Comparative analysis and interrater reliability of the Oshkosh Social Behaviors Scale for dementia patients. Poster presented at the Gerontological Society of America Conference, San Francisco, CA.

Marcos, T. (2002). La normalización y el diseño para todos [Normalization and design for all]. Minusval, 133, 28-30.

Meiland, F.J.M., Reinersmann, A., Bergvall-Kareborn, B., Craig, D., Moelaert, F., Mulvenna, M.D.,, ... Dröes, R.M. (2007). COGKNOW development and evaluation of an ICT-device for people with mild dementia. Studies In Health Technology And Informatics, 127, 166-177.

Nijhof, N., van Hoof, J., van Rijn, H., \& van Gemert-Pijnen, J.E.W.C. (2013). The behavioral outcomes of a technology-supported leisure activity in people with dementia. Technology \& Disability, 25(4), 263-273. doi:10.3233/tad-140398

Oriani, M., Moniz-Cook, E., Binetti, G., Zanieri, G., Frisoni, G.B., Geroldi, C., ... Zanetti, O. (2003). An electronic memory aid to support prospective memory in patients in the early stages of Alzheimer's disease: A pilot study. Aging \& Mental Health, 7(1), 22-27. doi:10.1080/1360786021000045863

Padilla, D. (2008). Tecnologías para mayores. [Tecnologies for the Elderly] Universitas Psychologica [online]. 7(3), 883-894.

Padilla, D., \& Sánchez-López, P. (2007). Necesidades educativas específicas: fundamentos psicológicos. [Specific educational needs: Psychological foundations]. Granada, Spain: Grupo Editorial Universitario.

Panza, F., Frisardi, V., Capurso, C., D'Introno, A., Colacicco, A.M., Imbimbo, B.P., ... Solfrizzi, V. (2010). Late-life depression, mild cognitive impairment, and dementia: Possible continuum?. The American Journal of Geriatric Psychiatry, 18(2), 98-116. doi:10.1097/ JGP.0b013e3181b0fa13

Piskur, B., Daniels, R., Jongmans, M.J., Ketelaar, M., Smeets, R.J., Norton, M., \& Beurskens, A.J. (2014). Participation and social participation: Are they distinct concepts? Clinical Rehabilitation, 28(3), 211-220. doi:10.1177/0269215513499029

Placencia, I. (2001). Nuevas tecnologías en Europa: E-Europe [New technologies in Europe: E-Europe]. Minusval. Instituto Nacional de Servicios Sociales (Inserso) 128, 18-19.

Riikonen, M., Paavilainen, E., \& Salo, H. (2013). Factors supporting the use of technology in daily life of home-living people with dementia. Technology \& Disability, 25(4), 233-243 211p. doi:10.3233/tad-130393

Roberts, R., \& Knopman, D.S. (2013). Classification and Epidemiology of MCI. Clinics in Geriatric Medicine, 29(4), 753-772. doi:10.1016/j. cger.2013.07.003

Sansoni, J., Marosszeky, N., Sansoni, E., \& Fleming, G. (2010). Final report: Effective assessment of social isolation. Wollongong: Centre for Health Service Development, University of Wollongong. Retrieved from http://ro.uow.edu.au/cgi/viewcontent cgi?article $=1472 \&$ context $=$ ahsri

Shankar, A., Hamer, M., McMunn, A., \& Steptoe, A. (2013). Social isolation and loneliness: Relationships with cognitive function during 4 years of follow-up in the English Longitudinal Study of Ageing. Psychosomatic Medicine, 75(2), 161-170. doi:10.1097/PSY.0b013e31827f09cd 
Spittlehouse, M.A.K.E.C. (2000). Introducing critical appraisal skills training in UK social services: Another link between health and social care? Journal of Interprofessional Care, 14(4), 397-404. doi:10.1080/ 13561820020003946

Takeda, M., Tanaka, T., Okochi, M., \& Kazui, H. (2012). Non-pharmacological intervention for dementia patients. Psychiatry and Clinical Neurosciences, 66(1), 1-7. doi:10.1111/j.1440-1819.2011.02304.x

United Nations (2015). World Population Ageing 2015. Retrieved from: http://www.un.org/en/development/desa/population/publications/ pdf/ageing/WPA2015_Report.pdf

Wang, B., He, P., \& Dong, B. (2015). Associations between social networks, social contacts, and cognitive function among Chinese nonagenarians/centenarians. Archives of Gerontology and Geriatrics, 60(3), 522527. doi:10.1016/j.archger.2015.01.002

Wiles, J.L., Leibing, A., Guberman, N., Reeve, J., \& Allen, R.E. (2011). The meaning of "aging in place" to older people. Gerontologist, 52(3), 357366. doi:10.1093/geront/gnr098

Wilson, R.S., Krueger, K.R., Arnold, S.E., Schneider, J.A., Kelly, J.F., Barnes, L. L., ... Bennett, D.A. (2007). Loneliness and risk of Alzheimer disease. Archives of General Psychiatry, 64(2), 234-240. doi:10.1001/ archpsyc.64.2.234

World Health Organization. (2015). Dementia 2015. Geneva: World Health Organization. Retrieved from http://www.who.int/mediacentre/fact sheets/fs362/en/

\section{Appendix 1. Non-pharmacological interventions}

\begin{tabular}{lccc}
\hline Therapy & Cognitive & ADL & BPSD \\
\hline Cognitive training & + & + & + \\
Cognitive rehabilitation & + & + & + \\
Cognitive stimulation therapy & + & + & + \\
Snoezelen/multisensory stimulation & + & + & + \\
Reality orientation & + & + & + \\
Reminiscence therapy & + & - & + \\
Validation therapy & + & - & + \\
Physical activity & + & + & + \\
Light therapy & + & - & + \\
Music therapy & + & - & + \\
Aromatherapy & - & - & + \\
Animal-assisted therapy & - & - & +
\end{tabular}

Notes: $A D L=$ activities of daily living; BPSD = behavioural and psychological symptoms of dementia (Takeda, Tanaka, Okochi, \& Kazui, 2012). 